\title{
Highly optimised complementary inverters based on p-SnO and n-InGaZnO With high uniformity
}

DOI:

10.1109/LED.2018.2809796

\section{Document Version}

Accepted author manuscript

Link to publication record in Manchester Research Explorer

\section{Citation for published version (APA):}

Jin, Y., Wang, Y., Li, Y., Yuan, Y., Hu, Z., Ma, P., Zhou, L., Qingpu Wang, Song, A., \& Qian Xin (2018). Highly optimised complementary inverters based on $\mathrm{p}-\mathrm{SnO}$ and $\mathrm{n}$-InGaZnO With high uniformity. IEEE Electron Device Letters, 39(4), 516 - 519. https://doi.org/10.1109/LED.2018.2809796

\section{Published in:}

IEEE Electron Device Letters

\section{Citing this paper}

Please note that where the full-text provided on Manchester Research Explorer is the Author Accepted Manuscript or Proof version this may differ from the final Published version. If citing, it is advised that you check and use the publisher's definitive version.

\section{General rights}

Copyright and moral rights for the publications made accessible in the Research Explorer are retained by the authors and/or other copyright owners and it is a condition of accessing publications that users recognise and abide by the legal requirements associated with these rights.

\section{Takedown policy}

If you believe that this document breaches copyright please refer to the University of Manchester's Takedown Procedures [http://man.ac.uk/04Y6Bo] or contact uml.scholarlycommunications@manchester.ac.uk providing relevant details, so we can investigate your claim.

\section{OPEN ACCESS}




\title{
Highly Optimised Complementary Inverters Based on $\mathrm{p}-\mathrm{SnO}$ and $\mathrm{n}-\mathrm{InGaZnO}$ with High Uniformity
}

\author{
Jin Yang, Yiming Wang, Yunpeng Li, Yuzhuo Yuan, Zhenjia Hu, Pengfei Ma, Li Zhou, Qingpu Wang, \\ Aimin Song, Senior Member, IEEE, and Qian Xin
}

\begin{abstract}
Oxide semiconductors are desirable for large-area and/or flexible electronics. Here, we report highly optimised complementary inverters based on n-type indium gallium zinc oxide and p-type tin monoxide thin-film transistors. Oxide-based inverters with a record voltage gain of 142 have been achieved. The switching point voltage has also been tuned to reach the ideal value, namely half value of the supply voltage. A narrow transition width of $1.04 \mathrm{~V}(13 \%$ of the supply voltage $)$ is achieved which offers a strong anti-jamming ability to avoid logic errors. Rail-to-rail output voltage swing has been achieved. The inverters still maintain high performance at a low supply voltage of $6 \mathrm{~V}$. A very large number of inverters have been fabricated and showed excellent uniformity in a working area of $1 \mathrm{~cm} \times 1 \mathrm{~cm}$. The switching point voltage and transition width show very small standard deviations of only $0.55 \%(0.022 \mathrm{~V})$ and $2.3 \%(0.024 \mathrm{~V})$, respectively, demonstrating promises for large-scale circuit integration.
\end{abstract}

Index Terms - Complementary inverter, indium gallium zinc oxide (IGZO), tin monoxide (SnO), thin-film transistor (TFT), uniformity, static voltage gain, noise margin.

\section{INTRODUCTION}

$\mathrm{O}$ XIDE semiconductors are highly attractive due to their unique advantages of high carrier mobility $(\sim 1 \sim 100$ $\left.\mathrm{cm}^{2} \mathrm{~V}^{-1} \mathrm{~s}^{-1}\right)$ in comparison to amorphous silicon and organic semiconductors, visible light transparency, and large-area and low-temperature processability $[1,2]$. Oxide-based inverters, which are the basic building blocks in both digital and analog circuits, have been intensively studied for phase reversals,

Manuscript received Jan. 19, 2018. This work was financed by the National Key Research and Development Program of China (Grant Nos. 2016YFA0301200 and 2016YFA0201800), the National Natural Science Foundation of China (Grant No. 11374185), Engineering and Physical Sciences Research Council (EPSRC) (Grant No. EP/N021258/1), China Postdoctoral Science Foundation funded project (2016M590634), the Key Research and Development Program of Shandong Province (2017GGX10111 and 2017GGX10121), the Natural Science Foundation of Jiangsu Province (BK20151255), Suzhou Planning Projects of Science and Technology (SYG201527 and SYG201616), and the Fundamental Research Funds of Shandong University (2016WLJH44).

J. Yang, Y. Wang, Y. Li, Y. Yuan, Z. Hu, P. Ma, L. Zhou, Q. Wang, A. Song and Q. Xin are with the Centre of Nanoelectronics, State Key Laboratory of Crystal Materials, and School of Microelectronics, Shandong University, Jinan 250100, China (e-mail:xinq@sdu.edu.cn). (Jin Yang and Yiming Wang are co-first authors.)

A. Song is with the School of Electrical and Electronic Engineering, University of Manchester, Manchester M13 9PL, UK amplifications, wave shaping, etc. Up to date, most reported inverters based on oxide semiconductors were composed by two n-type oxide thin-film transistors (TFTs) [3-8], due to the lack of high-performance p-type oxide TFTs. These inverters generally show a low voltage gain mainly due to their weak ability of logic pull-up. However, high voltage gain is critical for integrated circuits such as amplifiers, 6-transistor SRAM, high-order ring oscillators, etc. Complementary inverters have advantages of low power consumption, high voltage gain, good noise immunity, and wide output voltage swing, which are crucial in real applications. Recently, complementary inverters based on n-type oxides and p-type organic [9-17] or carbon nanotubes $[18,19]$ were fabricated. In these complementary inverters, low operation voltage $(\sim 3 \mathrm{~V})[9,12,14]$ and an extremely high voltage gain of 890 [15] have been achieved. However, stability and/or processing compatibility for large-scale integration are still big challenges.

Recently, several complementary inverters based on all oxide semiconductors have been demonstrated [2, 20-28]. Dindar et al. reported a complementary inverter employing n-type IGZO and p-type $\mathrm{Cu}_{2} \mathrm{O}$ [25]. The inverter showed a high voltage gain of 120 , but the switching point voltage was far from the half value of supply voltage. Chiu et al. have realized a complementary inverter based on n-type $\mathrm{ZnO}$ and p-type $\mathrm{SnO}$ with a high noise margin level, but the voltage gain is as low as 17 [24]. Overall, it is still challenging to simultaneously achieve high voltage gain, high noise margin level and satisfactory switching point voltage, which would require significant improvement of the on-off ratio, mobility, and subthreshold swing of p-type oxide TFTs. In addition, the uniformity of the reported oxide based inverters has hardly been tested in previous reports, but uniformity and reproducibility are extremely important for the large-scale integration and mass production. Furthermore, the environmental stability and bias stress stability should also be studied. Among the reported limited numbers of p-type oxide materials, $\mathrm{SnO}$ has been regarded as the most promising one due to its high hole mobility originated from the Sn delocalized 5s nature at the valence band maximum (VBM) [29]. By optimising the performance of p-type SnO TFTs [30], we have recently realized complementary inverters based on n-type IGZO and p-type $\mathrm{SnO}$ with a high voltage gain of 112 [31]. In this letter, we further improve the overall performance 
including higher voltage gain, better matching of switching pointing voltage, and higher noise margin level. More importantly, excellent uniformity reproducibility over a $1 \mathrm{~cm} \times$ $1 \mathrm{~cm}$ area has been demonstrated.

\section{EXPERIMENTAL}

Figure 1(a) shows a schematic diagram of a complementary inverter composed of an n-type IGZO and a p-type SnO TFT. First, a 5-nm-thick Ti layer for adhesion and a 30-nm-thick Au layer as the gate electrode were deposited on a $\mathrm{Si} / \mathrm{SiO}_{2}$ substrate by electron-beam evaporation. A 30-nm-thick $\mathrm{Al}_{2} \mathrm{O}_{3}$ was then deposited as the gate dielectric by atomic-layer deposition at $150{ }^{\circ} \mathrm{C}$. A p-type $\mathrm{SnO}$ layer with a thickness of $20 \mathrm{~nm}$ was deposited by radio-frequency magnetron reactive sputtering at room temperature [31]. The $\mathrm{SnO}$ films were annealed in the ambient air at $225^{\circ} \mathrm{C}$ for 2 hours. A 24-nm-thick n-type IGZO layer was then deposited by RF magnetron sputtering at room temperature [32]. $\mathrm{Ti}(50 \mathrm{~nm}) / \mathrm{Au}(30 \mathrm{~nm})$ were deposited as source/drain ohmic contacts by electron-beam evaporation. Finally, the sample was annealed at $150^{\circ} \mathrm{C}$ for 1 hour in the ambient air. The electrode and channel layers were patterned by UV lithography and lift off. The $\mathrm{Al}_{2} \mathrm{O}_{3}$ layer was patterned by UV lithography and inductively coupled plasma reactive ion etching. The electrical characteristics of TFT devices and complementary inverters were measured using a source/measure unit (Agilent B2902A) and oscilloscope (Keysight MSOX6004A) in dark at room temperature.

(a)
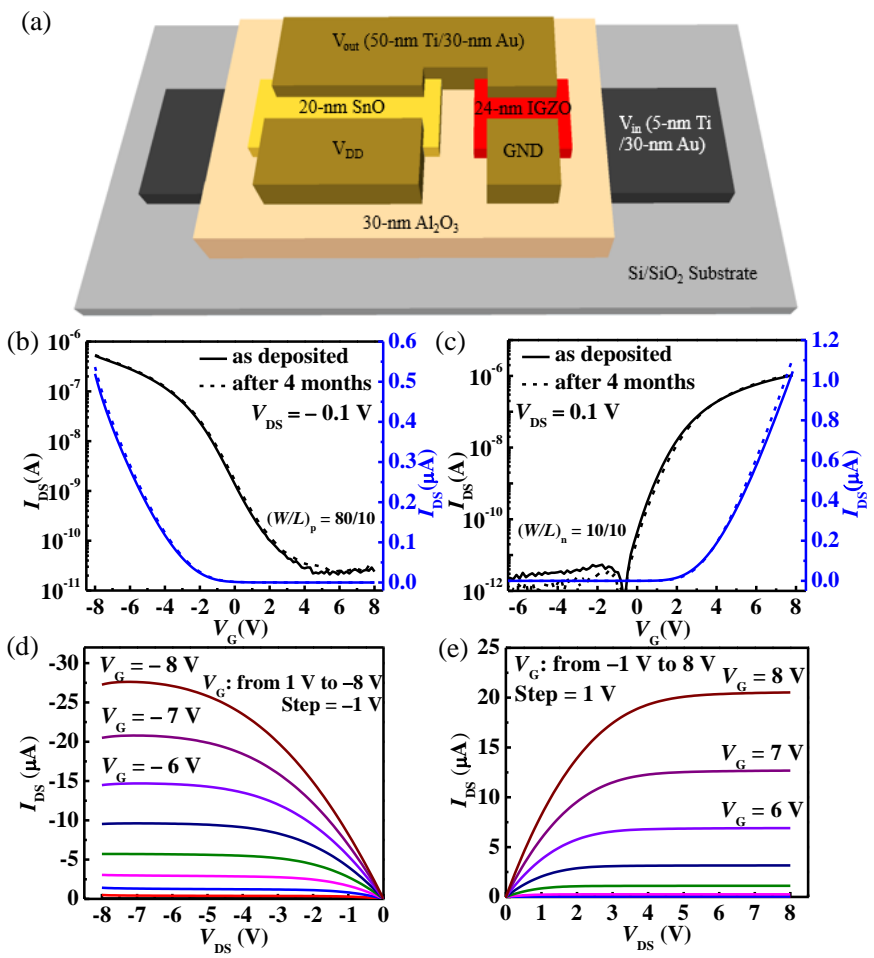

Fig. 1. (a) Schematic view of a complementary inverter based on an IGZO TFT and an $\mathrm{SnO}$ TFT on a $\mathrm{Si} / \mathrm{SiO}_{2}$ substrate. (b)(c) Transfer and (d)(e) output characteristics of the p-type SnO TFT and the n-type IGZO TFT, respectively.

\section{RESULTS AND DISCUSSION}

Figures 1(b) and (c) show the transfer characteristics of the $\mathrm{p}-\mathrm{SnO}$ and the n-IGZO TFTs at the drain-source voltage $\left(V_{\mathrm{DS}}\right)$ of $-0.1 \mathrm{~V}$ and $0.1 \mathrm{~V}$, respectively. The p-type TFT has an on/off current ratio of $2.6 \times 10^{4}$, which is, to the best of our knowledge, the highest value in the reported complementary oxide-based inverters [2, 20-28], a high linear mobility of $0.7 \mathrm{~cm}^{2} \mathrm{~V}^{-1} \mathrm{~s}^{-1}$, and a threshold voltage $\left(V_{\mathrm{TH}}\right)$ of $-4.8 \mathrm{~V}$. Subthreshold swing $(S S)$ was $1.4 \mathrm{~V} / \mathrm{dec}$, extracted from the linear portion of the $\log \left(I_{\mathrm{DS}}\right)$ versus $V_{\mathrm{G}}$ plot. The IGZO TFT has an on/off current ratio of $10^{6}$, a linear mobility of $8.2 \mathrm{~cm}^{2} \mathrm{~V}^{-1} \mathrm{~s}^{-1}$, a $V_{\mathrm{TH}}$ of $3.9 \mathrm{~V}$, and an $S S$ of $0.48 \mathrm{~V} / \mathrm{dec}$. The better $S S$ than what we reported before [31] is achieved by applying annealing at a higher temperature of $150{ }^{\circ} \mathrm{C}$ enabling a lower defect density in the channel. In addition, the TFTs show steady $I V$ characteristics after being kept in ambient air for 4 months as shown in Figs. 1(b) and (c), indicating a high environmental stability despite having no
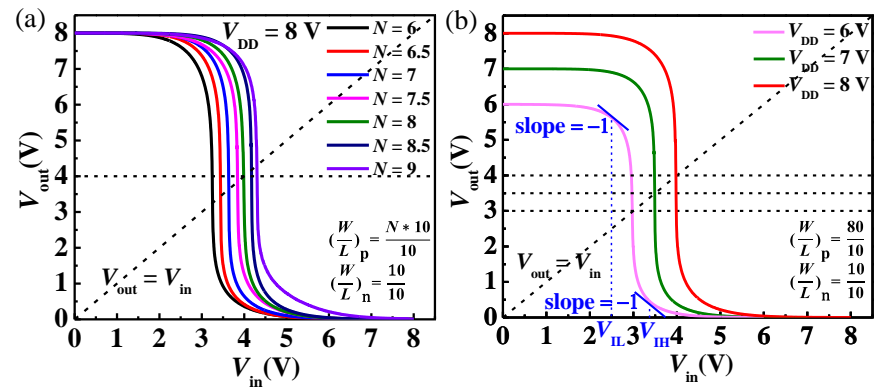

Fig. 2. Static voltage transfer characteristics of seven inverters with different geometric aspect ratios $N=(W / L)_{\mathrm{p}} /(W / L)_{\mathrm{n}}$ at a supply voltage of $8 \mathrm{~V}(\mathrm{a})$, and of the inverter with $N=8$ at different supply voltages of 6,7 and $8 \mathrm{~V}$ (b).

TABLE I

PROPERTIES OF THE INVERTER AT DIFFERENT SUPPLY VOLTAGES

\begin{tabular}{cccc}
\hline \hline & $V_{\mathrm{DD}}=6 \mathrm{~V}$ & $V_{\mathrm{DD}}=7 \mathrm{~V}$ & $V_{\mathrm{DD}}=8 \mathrm{~V}$ \\
\hline Gain & 75 & 129 & 137 \\
$V_{\mathrm{SP}}(\mathrm{V})$ & 2.97 & 3.48 & 3.98 \\
$N M_{\mathrm{H}}(\mathrm{V})$ & 2.57 & 3.06 & 3.55 \\
$N M_{\mathrm{L}}(\mathrm{V})$ & 2.50 & 3.01 & 3.43 \\
\hline \hline
\end{tabular}

encapsulation layer. The output curves of the $\mathrm{SnO}$ and IGZO TFTs indicate good Ohmic contacts between $\mathrm{Ti}$ and $\mathrm{SnO}$ and IGZO, plotted in Figs. 1(d) and (e).

To optimise the matching between the n- and p-type TFTs, we have optimised the geometric aspect ratio, $N$, defined as the width-to-length ratio of $\mathrm{SnO}$ TFT $(W / L)_{\mathrm{p}}$ divided by the width-to-length ratio of IGZO TFT $(W / L)_{n}$. The results of inverters with $N$ ranging from 6 to 9 at a supply voltage $\left(V_{\mathrm{DD}}\right)$ of $8 \mathrm{~V}$ are shown in Fig. 2(a). With the increase of $N$, the ability of logic pull-up by the SnO TFT becomes stronger. As a result, the static voltage transfer characteristics (VTCs) of the inverters move to the higher voltage direction. The optimised value of $N$ is 8 , since the curve of $N=8$ passes through the intersection point of $V_{\text {out }}=V_{\text {in }}$ and $V_{\text {out }}=V_{\mathrm{DD}} / 2$.

Figure 2(b) shows the static VTCs of inverters with $N=8$ at different $V_{\mathrm{DD}}$ of 6,7 , and $8 \mathrm{~V}$. The inverter performance is listed in Table I. The input-low voltage $\left(V_{\mathrm{IL}}\right)$ and the input-high voltage $\left(V_{\mathrm{IH}}\right)$ are the input voltage values at the points where $\mathrm{d} V_{\text {out }} / \mathrm{d} V_{\text {in }}=-1$. The output-low voltage $\left(V_{\mathrm{OL}}\right)$ and the output-high voltage $\left(V_{\mathrm{OH}}\right)$ reach $0 \mathrm{~V}$ and $\mathrm{V}_{\mathrm{DD}}$, respectively, thus achieving rail-to-rail output voltage swing. For $V_{\mathrm{DD}}=8 \mathrm{~V}$, the static voltage gain $\left(\left|\mathrm{d} V_{\text {out }} / \mathrm{d} V_{\text {in }}\right|\right)$, derived from the VTC, was 137, which is to the best of our knowledge, the highest gain among complementary oxide-based inverters up to date. It was 

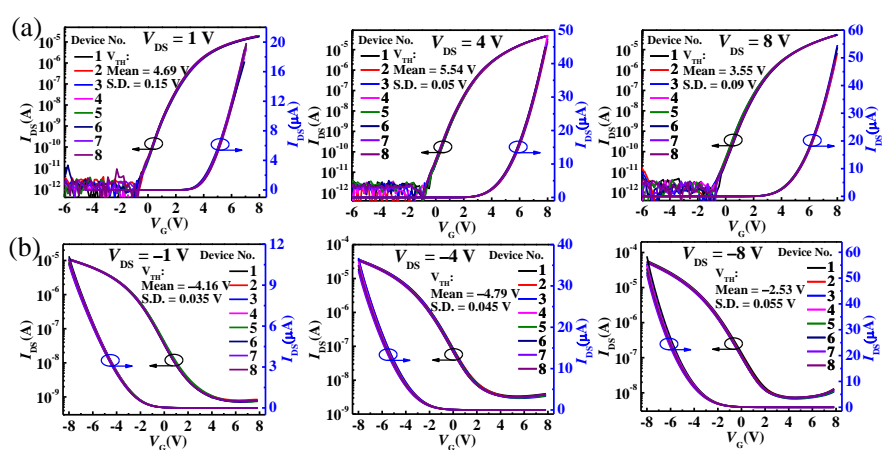

Fig. 3. Transfer curves of (a) eight IGZO TFTs $(W / L=30 \mu \mathrm{m} / 10 \mu \mathrm{m})$ and (b) eight SnO TFTs $(W / L=240 \mu \mathrm{m} / 10 \mu \mathrm{m})$ at different drain-source voltages, showing the mean value and standard deviation of $V_{\mathrm{TH}}$.
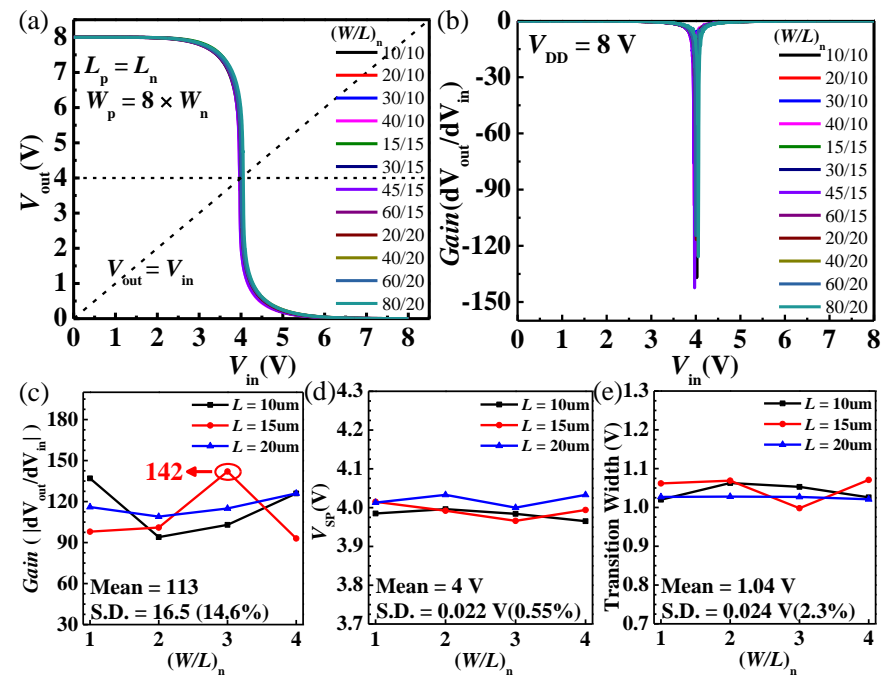

Fig. 4. Static voltage transfer characteristics (a) and Static voltage gains (b) of 12 inverters with different width-to-length ratios of IGZO TFTs and $N=8$ at a $V_{\mathrm{DD}}$ of $8 \mathrm{~V}$. The values of static voltage gain (c), switching point voltage (d), and transition width (e) of these 12 inverters.

calculated that the noise margin high $\left(N M_{\mathrm{H}}=V_{\mathrm{OH}}-V_{\mathrm{IH}}\right)$ was $3.55 \mathrm{~V}$, which is $44 \%$ of $V_{\mathrm{DD}}$, and the noise margin low $\left(N M_{\mathrm{L}}=\right.$ $\left.V_{\mathrm{IL}}-V_{\mathrm{OL}}\right)$ was $3.43 \mathrm{~V}$, around $43 \%$ of $V_{\mathrm{DD}}$. The large values suggest that the inverter can withstand a high noise level, and offer a strong anti-jamming ability to avoid logic errors. This is vitally important for reliable work of large-scale integrated circuits. The inverter shows a small hysteresis with $V_{\text {SP }}$ at 3.98 $\mathrm{V}$, an ideal value close to $V_{\mathrm{DD}} / 2$, in the forward scan, and $4.46 \mathrm{~V}$ in the reverse scan at $V_{\mathrm{DD}}=8 \mathrm{~V}$. Importantly, even if $V_{\mathrm{DD}}$ is as low as $6 \mathrm{~V}$, the inverter still maintains the $V_{\mathrm{SP}}$ at $V_{\mathrm{DD}} / 2$ and relatively high voltage gain of 75 .

The transfer curves of eight IGZO TFTs and eight SnO TFTs randomly selected in an area of $1 \mathrm{~cm} \times 1 \mathrm{~cm}$ under different $V_{\mathrm{DS}}$ values up to $8 \mathrm{~V}$ are characterized as shown in Fig. 3, demonstrating that these n-type and p-type TFTs have a high uniformity and almost constant $V_{\mathrm{TH}}$. Figures 4(a) and (b) display the static VTCs and voltage gains of 12 inverters with different width-to-length ratios of IGZO TFTs, $(W / L)_{\mathrm{n}}$ and $N=$ 8 at a $V_{\mathrm{DD}}$ of $8 \mathrm{~V}$. These inverters are randomly selected in a 1 $\mathrm{cm} \times 1 \mathrm{~cm}$ sample area. The 12 inverters show nearly uniform VTCs, as shown in Fig. 4(a). The results demonstrate not only robustness of the design at different channel lengths but also excellent uniformity over a large sample area. Figure 4(c) shows that the maximum gain is 142 . In Fig. $4(\mathrm{~d})$, the $V_{\mathrm{SP}}$ is $4 \mathrm{~V}$ in average, equal to the ideal value, with extremely small
TABLE II

SUMMARY OF THE PERFORMANCE OF COMPLEMENTARY OXIDE-BASED INVERTERS

\begin{tabular}{|c|c|c|c|c|c|}
\hline $\begin{array}{c}\text { Channel } \\
\text { materials }\end{array}$ & $\mathrm{V}_{\mathrm{DD}}(\mathrm{V})$ & Gain & $\mathrm{NM}_{\mathrm{H}}(\mathrm{V})$ & $\mathrm{NM}_{\mathrm{L}}(\mathrm{V})$ & Year \\
\hline $\begin{array}{l}\mathrm{n}-\mathrm{In}_{2} \mathrm{O}_{3} \\
\mathrm{p}-\mathrm{SnO}_{2}\end{array}$ & 100 & 11 & 40 & 22 & 2008 [20] \\
\hline $\begin{array}{l}\text { n-IGZO } \\
\text { p-Cu } \mathrm{Cu}_{2} \mathrm{O}\end{array}$ & 20 & 120 & 11.68 & 6.01 & 2011 [21] \\
\hline $\begin{array}{c}n-I G Z O \\
p-S n O_{X}(X<2)\end{array}$ & 17 & 4.2 & 6.5 & 0.6 & 2011 [22] \\
\hline $\begin{array}{c}\text { n-IGZO } \\
\text { p-SnO }\end{array}$ & 15 & 1.7 & 1.1 & -0.9 & $2012[2]$ \\
\hline $\begin{array}{c}n-I G Z O \\
p-S O_{X}(X<2)\end{array}$ & 17 & 4.9 & 9.8 & 1 & 2013 [23] \\
\hline $\begin{array}{l}\mathrm{n}-\mathrm{ZnO} \\
\mathrm{p}-\mathrm{SnO}\end{array}$ & 10 & 17 & 4.29 & 4.35 & 2014 [24] \\
\hline $\begin{array}{c}\mathrm{n}^{\mathrm{S}} \mathrm{SnO}_{\mathrm{X}} \\
\mathrm{p}-\mathrm{SnO}\end{array}$ & 10 & 3 & 2.7 & 1.2 & 2014 [25] \\
\hline $\begin{array}{l}\text { n-SnO } \\
\text { p-SnO }\end{array}$ & 40 & 102 & 7.3 & 14.9 & 2015 [26] \\
\hline $\begin{array}{l}\mathrm{n}-\mathrm{ZnO} \\
\mathrm{p}-\mathrm{SnO}\end{array}$ & 12 & 12 & 6.2 & 3.8 & $2016[27]$ \\
\hline $\begin{array}{c}\text { n-IGZO } \\
\text { p-SnO }\end{array}$ & 40 & 24 & 20 & 14.4 & 2017 [28] \\
\hline $\begin{array}{c}\text { n-IGZO } \\
\text { p-SnO }\end{array}$ & 8 & 142 & 3.6 & 3.4 & Our work \\
\hline
\end{tabular}

standard deviation (S.D.) of $0.022 \mathrm{~V}$. The transition width is $1.04 \mathrm{~V}\left(13 \%\right.$ of $\left.\mathrm{V}_{\mathrm{DD}}\right)$ in average with very small S.D. of 0.024 $\mathrm{V}$, indicating high noise margin level with high uniformity, as shown in Fig. 4(e). The inverters show relatively low power consumption, and the average power is $4 \mu \mathrm{W}$ when $V_{\text {in }}$ increases from 0 to $8 \mathrm{~V}$ to complete a logic inversion operation at $V_{\mathrm{DD}}=8 \mathrm{~V}$. A summary of the performance of complementary inverters based on all oxide semiconductors in recent years and our work is shown in Table II, showing that most key parameters are the best among complementary inverters based on all oxide semiconductors to date.

\section{CONCLUSION}

In this work, complementary inverters composed of n-type IGZO TFT and p-type SnO TFT were fabricated on a $\mathrm{Si} / \mathrm{SiO}_{2}$ substrate via a low-temperature process which can be directly applied to flexible substrates such as polyimide. To the best of our knowledge, these inverters have achieved the highest voltage gain at the lowest supply voltage, most optimised switching point voltage at half value of supply voltage, and very high noise margin level. Importantly, these inverters exhibit excellent uniformity over a large sample area of $1 \mathrm{~cm} \times$ $1 \mathrm{~cm}$. Our results indicate that complementary technology based on all oxide semiconductors is highly competitive and has great potential in future large-scale flexible and/or transparent integrated circuits.

\section{REFERENCES}

[1] T. Kamiya, K. Nomura, and H. Hosono, "Present status of amorphous In-Ga-Zn-O thin-film transistors," Sci Technol Adv Mater, vol. 11, no. 4, pp. 044305, Sep. 2010. doi:10.1088/1468-6996/11/4/044305

[2] E. Fortunato, P. Barquinha, and R. Martins, "Oxide semiconductor thin-film transistors: a review of recent advances," Adv Mater, vol. 24, no. 22, pp. 2945-86, Jun. 2012. doi:10.1002/adma.201103228

[3] D. P. Heineck, B. R. McFarlane, and J. F. Wager, "Zinc Tin Oxide Thin-Film-Transistor Enhancement/Depletion Inverter," IEEE Electron Device Letters, vol. 30, no. 5, pp. 514-516, May. 2009. doi:10.1109/led.2009.2017496 
[4] H. Yin, S. Kim, J. Park, I. Song, S. W. Kim, J. Hur, S. Park, S. Jeon, and C. J. Kim, "High Performance Low Voltage Amorphous Oxide TFT Enhancement/Depletion Inverter through Uni-/Bi-Layer Channel Hybrid Integration," 2009 Ieee International Electron Devices Meeting, pp. 199-202, Dec. 2009. doi:10.1109/iedm.2009.5424389

[5] M. J. Seok, M. H. Choi, M. Mativenga, D. Geng, D. Y. Kim, and J. Jang, "A Full-Swing a-IGZO TFT-Based Inverter With a Top-Gate-Bias-Induced Depletion Load," IEEE Electron Device Letters, vol. 32, no. 8, pp. 1089-1091, Aug. 2011. doi:10.1109/led.2011.2157798

[6] F. F. Vidor, T. Meyers, and U. Hilleringmann, "Inverter Circuits Using ZnO Nanoparticle Based Thin-Film Transistors for Flexible Electronic Applications," Nanomaterials (Basel), vol. 6, no. 9, Aug. 2016. doi:10.3390/nano6090154

[7] M. Wang, L. Liang, H. Luo, S. Zhang, H. Zhang, K. Javaid, and H. Cao, "Threshold Voltage Tuning in a-IGZO TFTs With Ultrathin SnOxCapping Layer and Application to Depletion-Load Inverter," IEEE Electron Device Letters, vol. 37, no. 4, pp. 422-425, Apr. 2016. doi:10.1109/led.2016.2525761

[8] S. Han, and S. Y. Lee, "Full swing depletion-load inverter with amorphous SiZnSnO thin film transistors," physica status solidi (a), vol. 214, no. 2, pp. 1600469, Nov. 2017. doi:10.1002/pssa.201600469

[9] M. S. Oh, K. Lee, K. H. Lee, S. H. Cha, J. M. Choi, B. H. Lee, M. M. Sung, and S. Im, "Transparent Photo-Stable Complementary Inverter with an Organic/Inorganic Nanohybrid Dielectric Layer," Advanced Functional Materials, vol. 19, no. 5, pp. 726-732, Mar. 2009. doi:10.1002/adfm.200801155

[10] K. Nomura, T. Aoki, K. Nakamura, T. Kamiya, T. Nakanishi, T. Hasegawa, M. Kimura, T. Kawase, M. Hirano, and H. Hosono, "Three-dimensionally stacked flexible integrated circuit: Amorphous oxide/polymer hybrid complementary inverter using n-type a-In-Ga-Zn-O and p-type poly-(9,9-dioctylfluorene-co-bithiophene) thin-film transistors," Applied Physics Letters, vol. 96, no. 26, pp. 263509 Jun. 2010. doi:10.1063/1.3458799

[11] D. I. Kim, B. U. Hwang, J. S. Park, H. S. Jeon, B. S. Bae, H. J. Lee, and N. E. Lee, "Mechanical bending of flexible complementary inverters based on organic and oxide thin film transistors," Organic Electronics, vol. 13, no. 11, pp. 2401-2405, Jul. 2012. doi:10.1016/j.orgel.2012.06.038

[12] G. Xiaojun, F. Linrun, C. Qingyu, and X. Xiaoli, "Low Voltage Organic/Inorganic Hybrid Complementary Inverter With Low Temperature All Solution Processed Semiconductor and Dielectric Layers," IEEE Electron Device Letters, vol. 35, no. 5, pp. 542-544, May. 2014. doi:10.1109/led.2014.2308210

[13] I. Isakov, A. F. Paterson, O. Solomeshch, N. Tessler, Q. Zhang, J. Li, X. Zhang, Z. Fei, M. Heeney, and T. D. Anthopoulos, "Hybrid complementary circuits based on p-channel organic and n-channel metal oxide transistors with balanced carrier mobilities of up to $10 \mathrm{~cm}^{2} / \mathrm{Vs}$," Applied Physics Letters, vol. 109, no. 26, pp. 263301, Dec. 2016. doi:10.1063/1.4972988

[14] Y. J. Jeong, T. K. An, D. J. Yun, L. H. Kim, S. Park, Y. Kim, S. Nam, K. H. Lee, S. H. Kim, J. Jang, and C. E. Park, "Photo-Patternable ZnO Thin Films Based on Cross-Linked Zinc Acrylate for Organic/Inorganic Hybrid Complementary Inverters," ACS Appl Mater Interfaces, vol. 8, no. 8, pp. 5499-508, Mar. 2016. doi:10.1021/acsami.6b00259

[15] S. Kumagai, H. Murakami, K. Tsuzuku, T. Makita, C. Mitsui, T. Okamoto, S. Watanabe, and J. Takeya, "Solution-processed organic-inorganic hybrid CMOS inverter exhibiting a high gain reaching 890," Organic Electronics, vol. 48, pp. 127-131, Jun. 2017. doi:10.1016/j.orgel.2017.05.050

[16] M. H. Lee, J. Kim, M. Kang, J. Kim, B. Kang, H. Hwang, K. Cho, and D. Y. Kim, "Precise Side-Chain Engineering of Thienylenevinylene-Benzotriazole-Based Conjugated Polymers with Coplanar Backbone for Organic Field Effect Transistors and CMOS-like Inverters," ACS Appl Mater Interfaces, vol. 9, no. 3, pp. 2758-2766, Jan. 2017. doi:10.1021/acsami.6b14701

[17] S. Sun, L. Lan, Y. Li, H. Ning, R. Yao, L. Wang, and J. Peng, "Stable ambipolar organic-inorganic heterojunction field-effect transistors and inverters with Cytop interlayer," RSC Advances, vol. 7, no. 10, pp. 5966-5969, Jan. 2017. doi:10.1039/c6ra26817j

[18] P. Vuttipittayamongkol, F. Wu, H. Chen, X. Cao, B. Liu, and C. Zhou, "Threshold voltage tuning and printed complementary transistors and inverters based on thin films of carbon nanotubes and indium zinc oxide," Nano Research, vol. 8, no. 4, pp. 1159-1168, Oct. 2014. doi:10.1007/s12274-014-0596-7
[19] W. Honda, T. Arie, S. Akita, and K. Takei, "Mechanically Flexible and High-Performance CMOS Logic Circuits," Sci Rep, vol. 5, pp. 15099, Oct. 2015. doi:10.1038/srep15099

[20] Dhananjay, C.-W. Chu, C.-W. Ou, M.-C. Wu, Z.-Y. Ho, K.-C. Ho, and S.-W. Lee, "Complementary inverter circuits based on $\mathrm{p}-\mathrm{SnO}_{2}$ and n- $\mathrm{In}_{2} \mathrm{O}_{3}$ thin film transistors," Applied Physics Letters, vol. 92, no. 23, pp. 232103, Jue. 2008. doi:10.1063/1.2936275

[21] A. Dindar, J. B. Kim, C. Fuentes-Hernandez, and B. Kippelen, "Metal-oxide complementary inverters with a vertical geometry fabricated on flexible substrates," Applied Physics Letters, vol. 99, no. 17, pp. 172104, Oct. 2011. doi:10.1063/1.3656974

[22] R. Martins, A. Nathan, R. Barros, L. Pereira, P. Barquinha, N. Correia, R. Costa, A. Ahnood, I. Ferreira, and E. Fortunato, "Complementary metal oxide semiconductor technology with and on paper," Adv Mater, vol. 23, no. 39, pp. 4491-6, Oct. 2011. doi:10.1002/adma.201102232

[23] R. F. P. Martins, A. Ahnood, N. Correia, L. M. N. P. Pereira, R. Barros, P. M. C. B. Barquinha, R. Costa, I. M. M. Ferreira, A. Nathan, and E. E. M. C. Fortunato, "Recyclable, Flexible, Low-Power Oxide Electronics," Advanced Functional Materials, vol. 23, no. 17, pp. 2153-2161, May. 2013. doi:10.1002/adfm.201202907

[24] I. C. Chiu, L. Yun-Shiuan, T. Min-Sheng, and I. C. Cheng, "Complementary Oxide-Semiconductor-Based Circuits With n-Channel ZnO and p-Channel SnO Thin-Film Transistors," IEEE Electron Device Letters, vol. 35, no. 12, pp. 1263-1265, Dec. 2014. doi:10.1109/led.2014.2364578

[25] P. K. Nayak, J. A. Caraveo-Frescas, Z. Wang, M. N. Hedhili, Q. X. Wang, and H. N. Alshareef, "Thin film complementary metal oxide semiconductor (CMOS) device using a single-step deposition of the channel layer," Sci Rep, vol. 4, pp. 4672, Apr. 2014. doi:10.1038/srep04672

[26] H. Luo, L. Liang, H. Cao, M. Dai, Y. Lu, and M. Wang, "Control of Ambipolar Transport in SnO Thin-Film Transistors by Back-Channel Surface Passivation for High Performance Complementary-like Inverters," ACS Appl Mater Interfaces, vol. 7, no. 31, pp. 17023-31, Aug. 2015. doi:10.1021/acsami.5b02964

[27] Y.-S. Li, J.-C. He, S.-M. Hsu, C.-C. Lee, D.-Y. Su, F.-Y. Tsai, and I. C. Cheng, "Flexible Complementary Oxide-Semiconductor-Based Circuits Employing n-Channel ZnO and p-Channel SnO Thin-Film Transistors," IEEE Electron Device Letters, vol. 37, no. 1, pp. 46-49, Jan. 2016. doi:10.1109/led.2015.2501843

[28] J. Zhang, J. Yang, Y. Li, J. Wilson, X. Ma, Q. Xin, and A. Song, "High Performance Complementary Circuits Based on p-SnO and n-IGZO Thin-Film Transistors," Materials (Basel), vol. 10, no. 3, Mar. 2017. doi: 10.3390/ma10030319

[29] Y. Ogo, H. Hiramatsu, K. Nomura, H. Yanagi, T. Kamiya, M. Hirano, and H. Hosono, "p-channel thin-film transistor using p-type oxide semiconductor, SnO,” Applied Physics Letters, vol. 93, no. 3, pp. 032113, Jul. 2008. doi:10.1063/1.2964197

[30] Y. Li, Q. Xin, L. Du, Y. Qu, H. Li, X. Kong, Q. Wang, and A. Song, "Extremely Sensitive Dependence of $\mathrm{SnO}_{\mathrm{x}}$ Film Properties on Sputtering Power," Sci Rep, vol. 6, pp. 36183, Nov. 2016. doi:10.1038/srep36183

[31] Y. Li, J. Yang, Y. Wang, P. Ma, Y. Yuan, J. Zhang, Z. Lin, L. Zhou, Q. Xin, and A. Song, "Complementary Integrated Circuits Based on p-Type $\mathrm{SnO}$ and n-Type IGZO Thin-Film Transistors," IEEE Electron Device Letters, vol. 39, no. 2, pp. 208-211, Dec. 2017. doi:10.1109/led.2017.2786237

[32] B. Zhang, H. Li, X. Zhang, Y. Luo, Q. Wang, and A. Song, "Performance regeneration of InGaZnO transistors with ultra-thin channels," Applied Physics Letters, vol. 106, no. 9, pp. 093506, Mar. 2015. doi:10.1063/1.4914296 